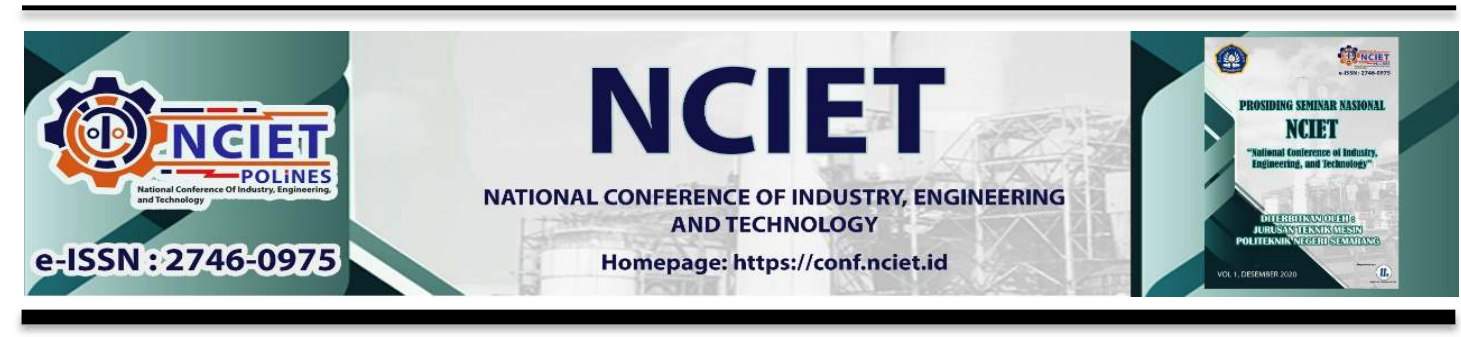

Prosiding Seminar Nasional NCIET Vol.1 (2020) B383-B389

$1^{\text {st }}$ National Conference of Industry, Engineering and Technology 2020, Semarang, Indonesia.

\title{
PENGENDALIAN MOTOR DC TERKENDALI JANGKAR DENGAN KONTROL PID YANG DITALA DENGAN CRAZINESS PARTICLE SWARM OPTIMIZATION (CRPSO)
}

\author{
Andi Imran', Firdaus ${ }^{2}$, Yanuar Mahfudz Safarudin ${ }^{3}$ \\ ${ }^{1,2}$ Pendidikan Teknik Elektro, Universitas Negeri Makassar \\ J1. A. P. Pettarani, Tidung, Rappocini, Makassar \\ ${ }^{3}$ Jurusan Teknik Mesin, Politeknik Negeri Semarang \\ Jl. Prof H. Soedarto, SH, Tembalang, Semarang, 50275 \\ E-mail: andi_imran@unm.ac.id, dauselektro@unm.ac.id
}

\begin{abstract}
Abstrak
Paper ini merepresentasikan simulasi pengendalian daur tertutup motor dc terkendali jangkar dengan kontrol PID. Tujuan penelitian ini untuk melihat perubahan kecepatan motor ketika diberi beban dengan menggunakan kontrol PID pada MATLAB. Pencarian nilai kontrol PID dilakukan secara otomatis dengan penalaan algoritma Craziness Particle Swarm Optimization (CRPSO). Hasil simulasi menunjukkan bahwa semakin besar beban maka kecepatan motor semakin lambat. Dengan pengendali PID yang ditala dengan CRPSO perubahan putaran terjadi pada durasi detik ke 18 sampai ke 24, dan putaran relatif dipertahankan pada putaran nominalnya.
\end{abstract}

Kata Kunci: Motor DC; PID; dan CRPSO.

\section{PENDAHULUAN}

Dewasa ini pengendalian kecepatan motor listrik memegang peranan penting pada dunia industri, karena motor DC mempunyai karakterristik kopel-kecepatan yang menguntungkan dibandingkan dengan motor AC. Tujuan dari pengontrol kecepatan motor adalah agar dapat menjalankan motor sesuai dengan kecepatan yang diinginkan, meskipun ada perubahan beban. Pada umumnya penerapan motor listrik bekerja pada tiga aspek operasi yaitu pada saat starting, pengedalian kecepatan dan pengereman. Dalam sistem pengendalian dikenal dua sistem yaitu pengendalian sistem daur terbuka (Open-Loop controller) dan pengendalian sistem daur tertutup (Closed-Loop Controller) [1]. Pada penelitian ini akan disimulasikan pengaturan kecepatan motor dc dengan sistem pengedalian daur tertutup (dengan umpan balik), dimana digunakan umpan balik untuk lebih memberikan pengaturan kecepatan yang lebih akurat atau mempertahankan kecepatan motor meskipun ada gangguan atau perubahan 
beban. Pada penelitian ini kontrol yang digunakan adalah PID [2]. Penalaan nilai kontoroler PID pada pengontrolan motor DC ini menggunakan Craziness Particle Swarm Optimization (CRPSO) [3].

\section{METODE PENELITIAN}

Pengendalian daur tertutup pada suatu sistem, dilakukan dengan memberikan umpan balik (feedback) dari output melalui sebuah sensor ke input sistem. Pada motor DC terkendali jangkar, variabel yang dikendalikan (controlled variabel) adalah kecepatan putar

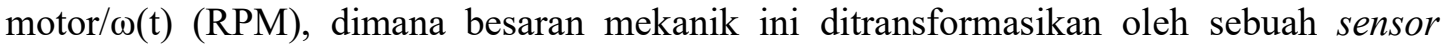
menjadi besaran listrik. Setelah itu, masuk ke dalam sebuah pengendali (controller) yang ditala dengan CRPSO. Dengan demikian setiap perubahan putaran motor DC dapat dimonitor oleh sensor untuk kemudian pengendali mengatur sedemikian rupa sehingga putaran motor diharapkan tetap konstan pada putaran nominalnya. Berdasarkan penjelasan tersebut di atas maka secara umum, diagram blok pengendalian daur tertutup dapat digambarkan sebagai berikut :

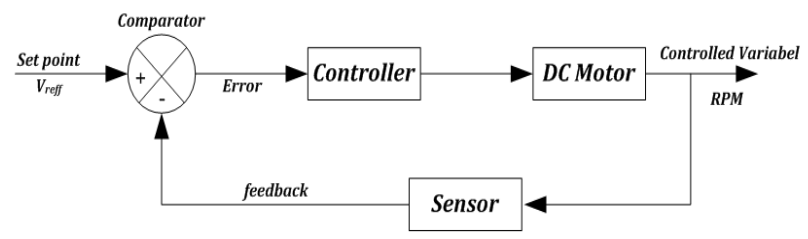

Gambar 1. Diagram blok pengendalian daur tertutup motor DC terkendali jangkar

\section{Model Dinamik}

Rumus penyusun rangkaian ekuivalen

a. Posisi sistem elektrik

$e a(t)-e b(t)=i a(t) R a+L a(d i(t) / d t)$

b. Pada posisi mekanik

$T(t)=J(d \omega(t) / d t)+B \omega(t)$

c. Sifat motor linier

$\mathrm{T}(\mathrm{t})=\mathrm{Km} \mathrm{Ia}(\mathrm{t})$

d. Sifat generator linier

$\mathrm{eb}(\mathrm{t})=\mathrm{Kb} \omega(\mathrm{t})$

Dari empat persamaan di atas diperoleh dua persamaan diferensial orde I

$$
\frac{d i_{a}(t)}{d t}=\frac{R_{a}}{L_{a}} i_{a}(t)-\frac{K_{B}}{L_{a}} \omega(t)+\frac{i}{L_{a}} e_{a}(t)
$$


$\frac{d \omega(t)}{d t}=\frac{K_{M}}{I} i_{a}(t)-\frac{B}{I} \omega(t)$

\section{Model simulink motor DC}

3.

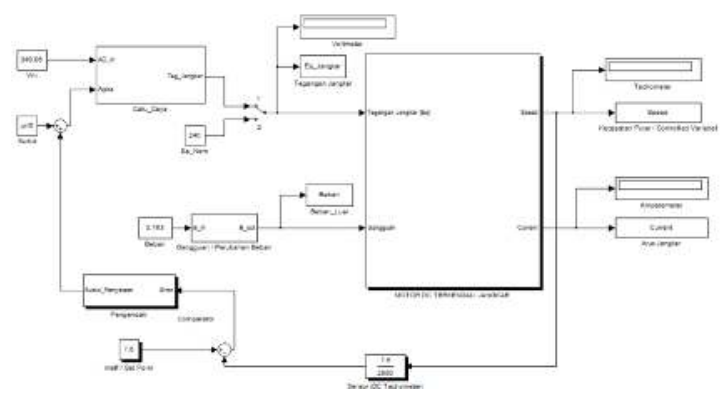

Gambar 2. Model simulink motor DC kondisi gangguan (dengan pengendalian)

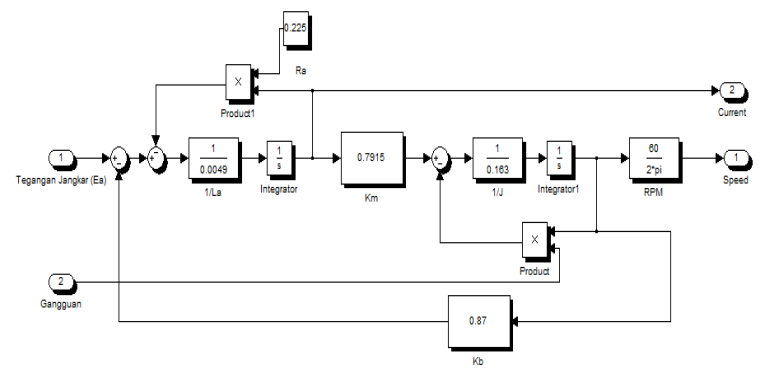

Gambar 3. Subsystem motor DC terkendali jangkar

\section{Algoritma Crazines Particles Swarm Optimization (CPSO)}

Pada prinsipnya kerja dari metode penalaan berbasis swarm intelligent khususnya Particle Swarm Optimization diawali dengan menyebarkan partikel dalam suatu ruang permasalahan. Ruang Permasalahan merupakan suatu daerah yang akan dioptimisasi nilainya. Pada Gambar 4 berikut ditampilkan suatu ruang permasalahan dengan hasil evaluasi fungsi objektif dalam bentuk grafik 3 dimensi. Pada Gambar tersebut ditampilkan suatu grafik 3 dimensi yang menunjukkan variasi perubahan kombinasi parameter terhadap hasil yang dicapai. Gambar menunjukkan suatu ruang permasalahan untuk menenmukan satu titik optimal dengan dua kombinasi variabel, dengan titik optimal ditampilkan pada sumbu $\mathrm{z}$ dan posisi partikel ditampilkan pada sumbu $\mathrm{x}$ dan $\mathrm{y}$.

Proses menemukan titik optimal pada Gambar tersebut adalah dengan menemukan kombinasi optimal dari nilai posisi $\mathrm{x}$ dan posisi y sehingga tepat menghasilkan solusi pada posisi z yang paling rendah. Proses untuk menemukan parameter ini ditempuh melalui penerapan Algoritma PSO maupun CRPSO. 


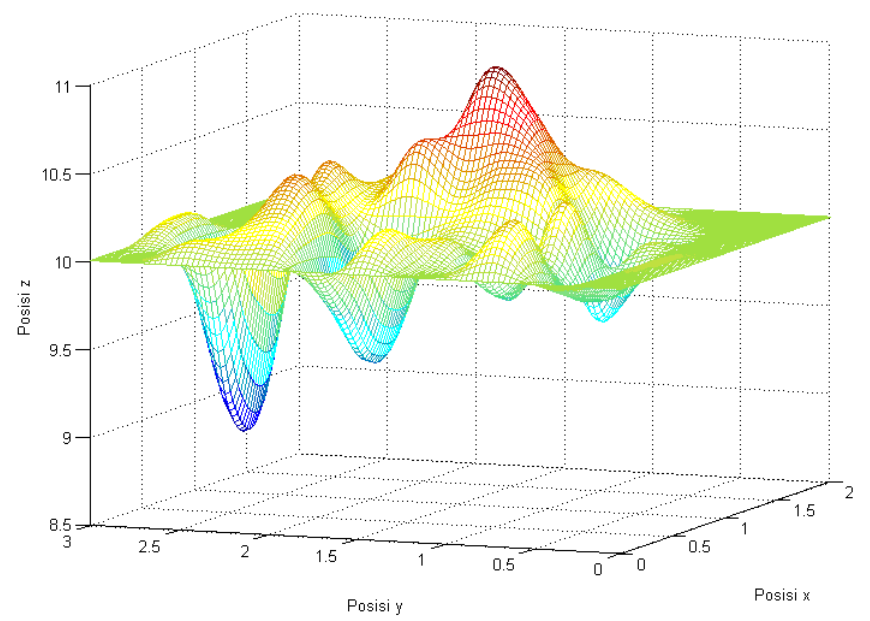

Gambar 4. Ruang Permasalahan dalam Proses Optimasi

Dari ilustrasi Gambar 4 diatas terlihat hasil nilai evaluasi pada setiap titik. Menggunakan ruang permasalahan yang sama diterapkan dua metode optimasi PSO dan CRPSO untuk mengamati kemampuan metode dalam mencapai nilai minimum. Tampilan gunung maupun danau pada gambar menunjukkan ketinggian maupun kedalaman dari hasil fungsi objektif. Kemudian partikel akan ditempatkan pada ruang permasalahan tersebut berdasarkan posisi $\mathrm{x}$ dan y untuk menentukan satu nilai terbaik berdasarkan hasil yang ditunjukkan pada posisi z. Misalkan nilai yang ingin dicapai adalah nilai minimum maka tujuan utama adalah menemukan daerah terdalam untuk setiap partikel. Setiap partikel kemudian akan bergerak untuk menemukan posisi terbaik sehingga tujuan akhir yang ingin dicapai adalah semua partikel berkumpul pada satu nilai minimum. Untuk menemukan nilai ini maka ada beberapa tahapan cara yang digunakan yaitu penyebaran partikel, evaluasi fungsi objektif, update velocity, update position, update local best, update global best, yang terakhir dipilih global best yang bertahan hingga akhir proses iterasi. Secara sederhana dapat dituliskan pada Diagram Alur pada Gambar 5 berikut [3]: 


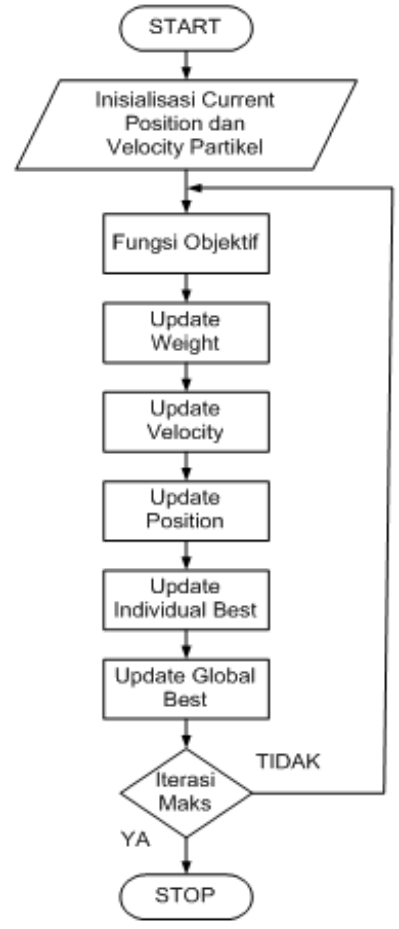

Gambar 5. Diagram Alur CRPSO

\section{HASIL DAN PEMBAHASAN}

Tabel 1.

\begin{tabular}{|c|c|c|c|c|}
\hline No & Besaran & Simbol & Volume & Satuan \\
\hline \multirow[t]{2}{*}{1} & \multirow[t]{2}{*}{ Daya } & \multirow[t]{2}{*}{$\mathrm{P}$} & 15 & HP \\
\hline & & & 11190 & Watt \\
\hline \multirow[t]{2}{*}{2} & \multirow{2}{*}{$\begin{array}{l}\text { kecepatan } \\
\text { Putar } \\
\text { Nominal }\end{array}$} & \multirow[t]{2}{*}{$\omega_{\text {nom }}$} & 2500 & Rpm \\
\hline & & & 261.799 & $\mathrm{Rad} / \mathrm{sec}$ \\
\hline 3 & $\begin{array}{l}\text { Tegangan } \\
\text { jangkar }\end{array}$ & $E_{a}$ & 240 & Volt \\
\hline 4 & Arus Jangkar & $I_{a}$ & 54 & Ampere \\
\hline 5 & $\begin{array}{l}\text { Tahanan } \\
\text { jangkar }\end{array}$ & $R_{a}$ & 0.225 & $0 \mathrm{hm}$ \\
\hline 6 & $\begin{array}{l}\text { Induktansi } \\
\text { Jangkar }\end{array}$ & $L_{a}$ & 0.0049 & Henry \\
\hline \multirow[t]{2}{*}{7} & \multirow{2}{*}{$\begin{array}{l}\text { Momen } \\
\text { Inersia }\end{array}$} & \multirow[t]{2}{*}{$\mathrm{J}$} & 1.50 & ${\mathrm{Lb} . \mathrm{Ft}^{2}}^{2}$ \\
\hline & & & 0.0633 & N.m.Sec ${ }^{2} / \mathrm{rad}$ \\
\hline
\end{tabular}




\begin{tabular}{|l|l|c|l|l|}
\hline 8 & $\begin{array}{l}\text { Konstanta } \\
\text { Gesekan }\end{array}$ & B & 0.163 & N.m.Sec/rad \\
\hline 9 & $\begin{array}{l}\text { Konstanta } \\
\text { Motor }\end{array}$ & $K_{m}$ & 0.7915 & N.m/Amp \\
\hline 10 & $\begin{array}{l}\text { Konstanta } \\
\text { GGL Lawan }\end{array}$ & $K_{b}$ & 0.870 & Volt.sec/rad \\
\hline 11 & TorsiNominal & $T_{m}$ & 42.7427 & N.m/rad \\
\hline
\end{tabular}

simulasi dilakukan selama 40 detik dengan asumsi bahwa motor telah berputar pada kecepatan nominalnya (2500 RPM) kemudian diberi tiga variasi perubahan beban. Variasi pertama (kenaikan beban 50\%) pada detik-3 selama 6 detik, variasi kedua (penurunan beban $40 \%$ ) pada detik ke-18 sampai ke-24 dan variasi ketiga (kenaikan beban 20\%) pada detik ke-30 sampai ke-36.

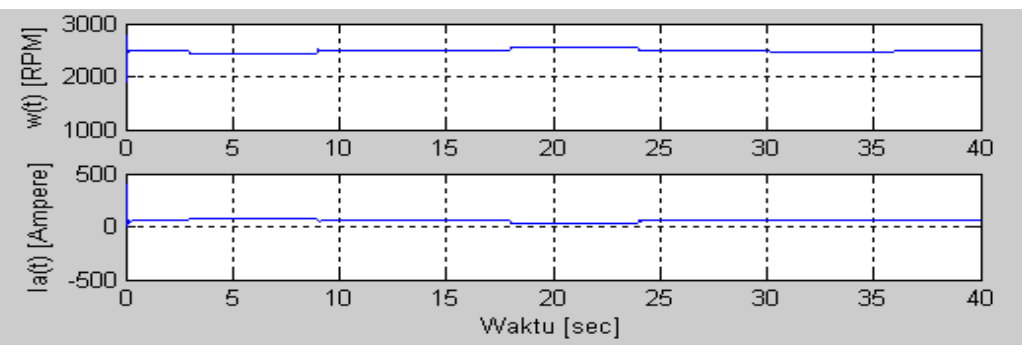

Gambar 6. Grafik hasil simulasi motor DC pada kondisi gangguan (tanpa pengendalian)

Grafik di atas memperlihat dengan jelas bahwa dengan naiknya beban maka putaran motor akan turun (menjadi lebih lambat), sebaliknya jika beban turun maka putaran motor akan naik (menjadi lebih cepat). Dari gambar diatas bahwa semakin besar beban maka kecepatan motor semakin lambat.

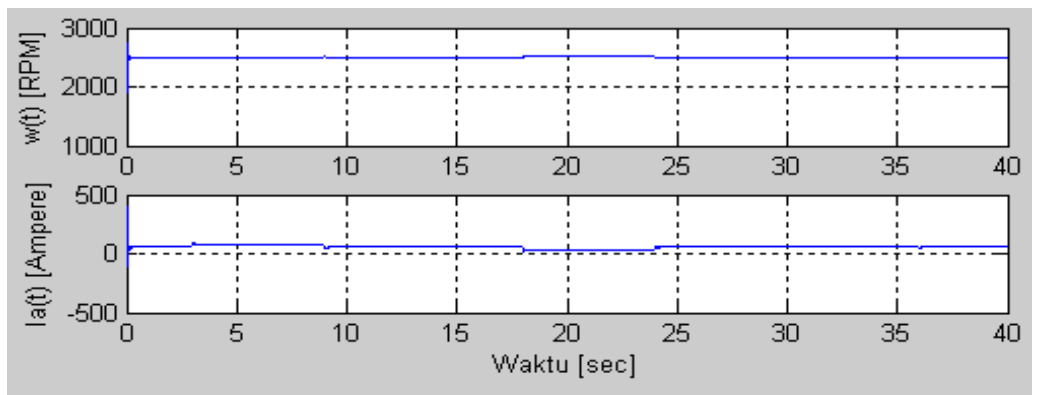

Gambar 7. Hasil simulink motor de dengan pengendali PID yang ditala dengan CRPSO Grafik Pada gambar 7 memperlihatkan bahwa dengan pengendali proporsional (PID) yang ditala dengan crpso perubahan putaran dapat dikurangi artinya cenderung mempertahankan putarannya. Hanya pada durasi detik ke 18 sampai ke 24 yang terlihat jelas perubahan putarannya. 


\section{KESIMPULAN}

Hasil Simulink motor DC tanpa pengendali menunjukkan bahwa putaran motor akan berubah sesuai dengan perubahan beban, sedangkan dengan pengendali putaran relatif dipertahankan pada putaran nominalnya. Lalu pengendalian dibuat otomatis dengan penalaan Crazines Particle Swarm Optimization (CPSO) sehingga menghasilkan nilai yang optimize.

\section{DAFTAR PUSTAKA}

[1]. Katsuhiko Ogata, “Teknik Kontrol Automatik”, Erlangga Jakarta. 1997

[2]. Karl Johan Astrom and Tore Hagglund, "Advanced PID Control” ISA United States of America. 2006

[3]. Krishna Teerth Chaturvedi, Manjaree Pandit, Laxmi Srivastava, Particle Swarm Optimization with Crazy Particle for Nonconvex Economic Dispath, Applied Soft Computing Journal, 2008. 